\title{
Suppression of PKCE-mediated mitochondrial connexin 43 phosphorylation at serine 368 is involved in myocardial mitochondrial dysfunction in a rat model of dilated cardiomyopathy
}

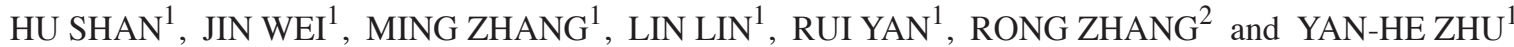 \\ ${ }^{1}$ Department of Cardiology, The Second Affiliated Hospital, Xi'an Jiaotong University School of Medicine, \\ Xi'an, Shaanxi 710004; ${ }^{2}$ Department of Gastroenterology, Shaanxi Provincial People's Hospital, \\ Xi'an, Shaanxi 710068, P.R. China
}

Received March 27, 2014; Accepted January 2, 2015

DOI: $10.3892 / \mathrm{mmr} .2015 .3260$

\begin{abstract}
Mitochondrial connexin 43 (Cx43) is important in cardioprotection by ischemic preconditioning; however, whether mitochondrial $\mathrm{Cx} 43$ is involved in mitochondrial dysfunction in the pathogenesis of dilated cardiomyopathy (DCM) remains to be elucidated. The present study was performed to investigate the changes in expression and the phosphorylation state of mitochondrial $\mathrm{Cx} 43$ in a rat model of DCM, and to determine whether the altered phosphorylation state of mitochondrial $\mathrm{Cx} 43$ was involved in mitochondrial dysfunction. A rat model of DCM was generated by daily oral administration of furazolidone (FZD) for 30 weeks. Reverse transcription polymerase chain reaction and western blot analysis revealed a decrease in the overall expression of $\mathrm{Cx} 43$, accompanied by reduced levels of serine 368-phosphorylated-Cx43 immunoreactivity in the myocardium and myocardial mitochondria. In addition, the mitochondrial membrane potential and the activities of cytochrome $c$ oxidase, succinate dehydrogenase and protein kinase $\mathrm{C}(\mathrm{PKC}) \varepsilon$ were all significantly reduced compared with those of the control group. Phorbol-12-myristate-13-acetate (PMA), a specific PKC activator, partially reversed the FZD-induced mitochondrial $\mathrm{Cx} 43$ dephosphorylation at serine 368 and mitochondrial dysfunction in the cardiomyocytes. However, pretreatment with $18 \beta$-glycerrhetinic acid, a connexin channel inhibitor, eliminated the mitochondrial protective effect of PMA in the cardiomyocytes sparsely plated without cell to cell contact. These results suggested that dephosphorylation of mitochondrial $\mathrm{Cx} 43$ at serine 368 , due to the suppression of
\end{abstract}

Correspondence to: Dr Jin Wei, Department of Cardiology, The Second Affiliated Hospital, Xi'an Jiaotong University School of Medicine, 157 Xiwu Road, Xi'an, Shaanxi 710004, P.R. China E-mail: yaosha1861@aliyun.com

Key words: connexin 43, mitochondria, protein kinase Ce, dilated cardiomyopathy
PKC $\varepsilon$ activity, may be a novel mechanism for mitochondrial dysfunction in the pathogenesis of DCM.

\section{Introduction}

Connexin $43(\mathrm{Cx} 43)$ is the predominant connexin in the ventricles is a phosphoprotein, the properties of which are affected by its phosphorylation state (1). Cx43 is primarily located in the sarcolemma of cardiomyocytes, and sarcolemmal Cx43 is important in electrical cell coupling through the formation of a gap junction (1). A previous study demonstrated that $\mathrm{Cx} 43$ was also present in the mitochondria of cardiomyocytes, with phosphorylation of $>80 \%$ of the mitochondrial Cx43 (mtCx43) (2). In addition, a normal mtCx43 content is essential for ischemic preconditioning-induced cardioprotection (3). It has been reported that cardiomyocytes of heterozygous $\mathrm{Cx} 43$-deficient mice have a functional deficit in diazoxide-induced cardioprotection (4). By contrast, the mitochondria-specific transgenic overexpression of $\mathrm{Cx} 43$ triggers cytoprotection, induced by preconditioning (5). Increasing evidence has indicated that $\mathrm{mtCx} 43$ is an important sensor of cardioprotective signals and may be involved in cardiomyocyte pathophysiology. However, whether mtCx43 is involved in the pathogenesis of dilated cardiomyopathy (DCM) and its correlation with mitochondrial dysfunction in cardiomyocytes remain to be fully elucidated.

DCM is the most prevalent type of cardiomyopathy worldwide and mitochondrial dysfunction is reported to be the major mechanism responsible for the development of this disease (6). In order to investigate the mechanism underlying mitochondrial dysfunction in DCM, a rat model of DCM was established in a previous study by daily oral administration of furazolidone (FZD) for 30 weeks. This procedure resulted in apparent mitochondrial dysfunction in the myocardium, accompanied by increasing left ventricle dimensions and reduced systolic and diastolic functions (7).

The aim of the present study was to investigate the role of $\mathrm{mtCx} 43$ in mitochondrial dysfunction during the pathogenesis of DCM. Therefore, the present study examined the expression and phosphorylation state of $\mathrm{mtCx} 43$ in 
the FZD-treated rat heart and cardiomyocytes, the role of protein kinase $\mathrm{C}(\mathrm{PKC}) \varepsilon$ in the phosphorylation of $\mathrm{mtCx} 43$ in rat cardiomyocytes and the impact of $\mathrm{mtCx} 43$ suppression on $\mathrm{PKC} \varepsilon$ activator-induced mitochondrial protection in the FZD-treated cardiomyocytes.

\section{Materials and methods}

Animal model. The present study was approved by the Institutional Animal Research and Ethics Committee of Xi'an Jiaotong University School of Medicine (Xi'an, China). A total of 36 Sprague-Dawley rats (3 weeks), weighing between 40 and $60 \mathrm{~g}$, were provided by the Animal Center of Xi'an Jiaotong University School of Medicine and were randomly divided into two groups. The rats were housed individually and provided with ad libitum access to food and water in a temperature-controlled room $\left(22 \pm 2^{\circ} \mathrm{C}\right)$, under a 12-h light/dark cycle (lights on at 08:00 a.m.). The 24 rats in the FZD group received 700 ppm orally administered FZD solution (Yunpeng Pharmacy Co., Ltd, Shaanxi, China) dissolved in water daily for 30 weeks and the 12 rats in the control group received tap water only. Echocardiographic investigations (iE33; Philips, Amsterdam, Netherlands) were performed in order to identify whether the DCM model was successfully established, as previously described (7).

Cell culture and treatment. Primary culture of neonatal rat cardiomyocytes were prepared and characterized, as previously described (7). The cardiomyocytes were sparsely plated without cell-cell contact and were cultured in Dulbecco's modified Eagle's medium (DMEM)/F12 (HyClone Laboratories, Inc., Waltham, MA, USA) containing 10\% heat-inactivated fetal bovine serum (FBS; Gibco-BRL, Carlsbad, CA, USA), $100 \mathrm{U} / \mathrm{ml}$ penicillin (HyClone; Thermo Fisher Scientific, Waltham, MA, USA) and $100 \mu \mathrm{g} / \mathrm{ml}$ streptomycin sulfate (HyClone) at $37^{\circ} \mathrm{C}$ with $5 \%$ $\mathrm{CO}_{2}$. Prior to treatment, the cells were starved for $24 \mathrm{~h}$ in DMEM/F12 medium containing 0.5\% FBS. Subsequently, the cells were divided into four groups, as follows: Control group, incubated with vehicle only; FZD group, incubated with $100 \mu \mathrm{mol} / \mathrm{l} \mathrm{FZD} \mathrm{(Sigma-Aldrich,} \mathrm{St.} \mathrm{Louis,} \mathrm{MO,}$ USA) for $48 \mathrm{~h}$; PMA group, incubated with $100 \mathrm{mmol} / 1$ phorbol-12-myristate-13-acetate (PMA; Sigma-Aldrich), a specific PKC activator, for $60 \mathrm{~min}$ following $48 \mathrm{~h}$ treatment with $100 \mu \mathrm{mol} / 1 \mathrm{FZD}$; $18 \beta$-glycerrhetinic acid (GA) group, successively treated with $100 \mu \mathrm{mol} / 1 \mathrm{FZD}$ for $48 \mathrm{~h}, 50 \mu \mathrm{mol} / 1$ GA (Sigma-Aldrich), a connexin channel inhibitor, for $4 \mathrm{~h}$ and $100 \mathrm{nmol} / \mathrm{l} \mathrm{PMA}$ for $60 \mathrm{~min}$.

Isolation of mitochondria. Mitochondria were isolated from the left ventricles of the rats and the cultured cardiomyocytes through differential centrifugation, as previously described (7). Briefly, the rats were narcotized with $30 \mathrm{mg} / \mathrm{kg}$ nembutal (Sigma-Aldrich) and the thorax was opened, in order to excise the heart. The arterial and vessel tissues were removed, and the ventricular tissues were retained and cut into $1 \mathrm{~mm}$ sections. The homogenates were centrifuged at $1,000 \mathrm{x} \mathrm{g}$ for $10 \mathrm{~min}$ and the supernatant was then centrifuged at 10,000 x g for $10 \mathrm{~min}$. Subsequently, the sediment was suspended in isolation buffer $(300 \mathrm{mmol} / \mathrm{l}$ sucrose, 2 mmol/1 HEPES, 0.1 mmol/1 EGTA, pH 7.4; Shanghai Genmed Gene Pharmaceutical Technology Co., Ltd., Shanghai, China) and added to the top of $30 \%$ percoll solution (Sigma-Aldrich) for centrifugation at 35,000 x g for $30 \mathrm{~min}$. The mitochondrial fraction was collected and washed twice using isolation buffer through centrifugation at $8,000 \mathrm{x} \mathrm{g}$ for $5 \mathrm{~min}$.

Mitochondrial membrane potential assay. JC-1 dye (Invitrogen Life Technologies, Carlsbad, CA, USA) was used to assess the mitochondrial membrane potential (MMP) level through the measurement of quantitative fluorescence. The freshly isolated rat myocardial mitochondria or cultured cardiomyocytes were incubated at $37^{\circ} \mathrm{C}$ for $10 \mathrm{~min}$ in DMEM/F12 medium containing $10 \mu \mathrm{g} / \mathrm{ml} \mathrm{JC}-1$. Subsequently, the mitochondria or cardiomyocytes were rinsed twice with phosphate-buffered saline and then scanned in a fluorescence microplate reader (Infinite M200; Tecan Inc., Maennedorf, Switzerland) at $488 \mathrm{~nm}$ excitation and $535 \mathrm{~nm}$ or $590 \mathrm{~nm}$ emission, respectively.

Enzyme activities measurement. The activities of cytochrome $c$ oxidase (COX) and succinate dehydrogenase (SDH) were determined using $\mathrm{COX}$ and SDH quantitative colorimetric assay kits (Genemed Co., Ltd, Shanghai and Jiancheng Chemical Industrial Co., Ltd, Nanjing, China, respectively) according to the manufacturer's instructions. The activity of COX was calculated according to changes in absorbance at $550 \mathrm{~nm}$, measured using a spectrophotometer. The activity of SDH was determined by the speed of the 2,6-dichlorophenol-indophenol reduction reaction (the change in absorbance value at the same time), accompanied by the reduction of flavin adenine dinucleotide (FAD) to FADH.

Reverse transcription quantitative polymerase chain reaction $(R T-q P C R)$. Total RNA was isolated from the rat left ventricle tissues and cardiomyocytes using TRIzol reagent (Invitrogen Life Technologies) and then $1 \mu \mathrm{g}$ total RNA was reverse transcribed into cDNA using a cDNA Synthesis kit (Fermentas; Thermo Fisher Scientific), according to the manufacturer's instructions. The cDNA was amplified using the appropriate primers and the SYBR Premix Ex Taq ${ }^{\mathrm{TM}}$ II (Takara Biotechnology Co., Ltd., Dalian, China). qPCR reactions were carried out with an initial denaturation at $95^{\circ} \mathrm{C}$ for $30 \mathrm{sec}$, followed by 40 cycles consisting of: Denaturing at $95^{\circ} \mathrm{C}$ for $5 \mathrm{sec}$, annealing at $60^{\circ} \mathrm{C}$ for $30 \mathrm{sec}$, and extension at $72^{\circ} \mathrm{C}$ for $30 \mathrm{sec}$, followed by a melting curve analysis, on an $\mathrm{iCycler}_{\mathrm{iQ}} \mathrm{Q}^{\mathrm{TM}}$ Real Time PCR Detection system (Bio-Rad Laboratories, Inc., Hercules, CA, USA). The primers were as follows: Cx43, forward 5'CATGGGTGACTGGAG-3' and reverse 5'-AGGACCCAGAAGCGCA-3'; glyceraldahyde-3-phosphate dehydrogenase (GADPH), forward 5'-TTGTGATGGGTGTGAACC-3' and reverse 5'-TTCTGAGTGGCAGTGATG-3' (Takara Biotechnology Co., Ltd.). The amount of relative gene expression was calculated by $2-\Delta \Delta \mathrm{Ct}$.

Western blot analysis. The proteins $(20 \mu \mathrm{g})$ were electrophoresed on 8 or 10\% SDS-PAGE (Xi'an Wolsen Bio-technology, 
Co., Ltd., Xi'an, China) and transferred onto a polyvinylidene difluoride membrane (Millipore, Bedford, MA, USA). The membrane was incubated with $5 \%$ non-fat dry milk in Tris-buffered saline solution for $2 \mathrm{~h}$, followed by the addition of the following antibodies: Rabbit polyclonal Cx43 (1:500; cat. no. sc-9059, Santa Cruz Biotechnology, Inc., Dallas, TX, USA), rabbit polyclonal serine 368-phosphorylated Cx43 (p-S368 Cx43; 1:200; cat. no. sc-25165-R, Santa Cruz Biotechnology, Inc.), rabbit monoclonal PKCE (1:1,000; cat. no. 2683, Cell Signaling Technology, Inc., Danvers, MA, USA), rabbit monoclonal p- myristoylated alanine-rich C kinase substrate (p-MARCKS; 1:1,000; cat. no. 11992, Cell Signaling Technology, Inc.), mouse monoclonal voltage-dependent anion channels (VDAC; 1:3,000; cat. no. sc-390996, Santa Cruz Biotechnology, Inc.) or mouse monoclonal $\beta$-actin (1:2,000; cat. no. sc-47778, Santa Cruz Biotechnology, Inc.) at $4^{\circ} \mathrm{C}$ overnight. The membranes were then incubated with peroxidase-conjugated secondary antibodies (1:4,000-1:10,000; cat. nos. sc-2370/1, Santa Cruz Biotechnology) at room temperature for $2 \mathrm{~h}$. The blots were visualized using an enhanced chemiluminescence detection system (Pierce Biotechnology, Inc., Shaanxi, China). $\beta$-actin and VDAC were used as loading control for the whole cellular and mitochondrial proteins, respectively.

Statistical analysis. Data from three independent experiments are expressed as the mean \pm standard deviation and statistical analyses were performed using SPSS 17.0 software (SPSS, Inc., Chicago, IL, USA). Differences between the groups were evaluated using one-way analysis of variance and a least significant difference test. $\mathrm{P}<0.05$ was considered to indicate a statistically significant difference.

\section{Results}

Mitochondrial dysfunction in the myocardium. Freshly isolated mitochondria from the left ventricles were stained with JC-1 to assess the MMP levels. Compared with those in the control group, the MMP levels were significantly decreased in the FZD group $(\mathrm{P}<0.05$; Fig. $1 \mathrm{~A})$. In addition, the activities of COX and SDH in the FZD group were significantly reduced $(\mathrm{P}<0.0$; Fig. $1 \mathrm{~B})$.

Expression of Cx43 in the myocardium and myocardial mitochondria. RT-qPCR analysis revealed that the mRNA expression of $\mathrm{Cx} 43$ in the left ventricle myocardium was markedly downregulated following treatment with FZD compared with that of the untreated control $(\mathrm{P}<0.05$; Fig. 2A). A marked reduction in the mRNA expression levels of $\mathrm{Cx} 43$ was also detected in the FZD-treated cardiomyoctes $(\mathrm{P}<0.05$; Fig. 2B). Western blot analysis identified three typical Cx43-specific bands in the myocardial protein extracts. The overall expression of $\mathrm{Cx} 43$ in the FZD group was significantly decreased compared with that of the control group $(\mathrm{P}<0.05$; Fig. 3). In addition, the phosphorylation status of $\mathrm{Cx} 43$ was analyzed using western blot analysis, which demonstrated that the immunoreactivity of p-S368 Cx43 was reduced by $37.7 \pm 4.4 \%$ in the myocardium following FZD treatment compared with that of the untreated control $(\mathrm{P}<0.05$; Fig. 3). As shown in Fig. 4, three typical $\mathrm{Cx} 43$-specific bands were also detected in the myocardial mitochondrial protein extracts and relatively low levels of
A

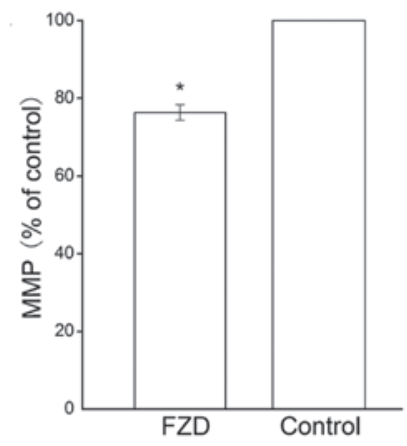

B

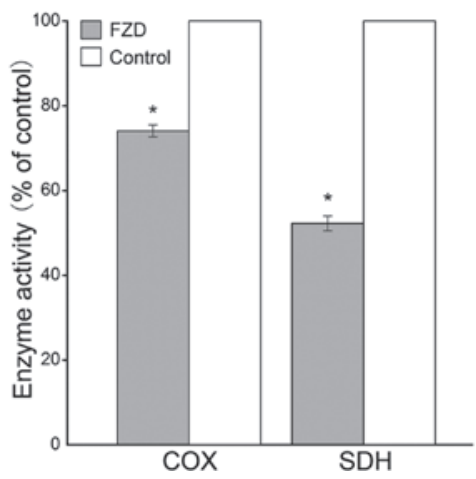

Figure 1. Mitochondrial function of the rat myocardium. (A) MMP levels and (B) activities of COX and SDH in the myocardial mitochondria of the FZD and control groups. Values are presented as the mean \pm standard deviation. ${ }^{*} \mathrm{P}<0.05$ vs. control. MMP, mitochondrial membrane potential; COX cytochrome $c$ oxidase; SDH, succinate dehydrogenase; FZD, furazolidone.

overall Cx43 and p-S368 Cx43 were observed in the FZD group compared with those in the control group $(\mathrm{P}<0.05)$.

Changes of expression and activity of PKCE in the myocardium andmyocardialmitochondria.PKC $\varepsilon$ is an important cardioprotective mediator, which interacts with $\mathrm{Cx} 43$ and is required for the phosphorylation of Cx43 at the S368 PKC target site (8). In the present study, the expression and activity of PKC $\varepsilon$ were examined using western blot analysis to determine whether PKC $\varepsilon$ mediated the phosphorylation of $\mathrm{Cx} 43$ at $\mathrm{S} 368$ in the myocardium and mitochondria. MARCKS is a major substrate of PKCE (9), therefore, p-MARCKS levels were detected in order to assess $\mathrm{PKC} \varepsilon$ activity. The results showed that the immunoreactivity of PKC $\varepsilon$ in the myocardial protein extracts was reduced by $25.1 \pm 2.7 \%$ in the FZD group compared with that of the control group $(\mathrm{P}<0.05$;Fig. 3), and the phosphorylation of MARCKS was significantly decreased by $61.6 \pm 3.4 \%$ ( $\mathrm{P}<0.05$; Fig. 3$)$. These changes indicated that FZD induced a marked decrease of PKC $\varepsilon$ activity in the myocardium. Furthermore, decreased protein expression of PKC $\varepsilon$ was detected in the myocardial mitochondrial protein extracts following treatment with FZD compared with that of the untreated control $(\mathrm{P}<0.05$; Fig. 4).

Changes of protein expression in FZD-treated cardiomyocytes. In order to investigate the possible mechanism underlying the mitochondrial dysfunction in the FZD-induced DCM rat model, neonatal rat cardiomyocytes were cultured and incubated with $100 \mu \mathrm{mol} / 1 \mathrm{FZD}$ for $48 \mathrm{~h}$. Western blot analyses revealed that the protein levels of $\mathrm{Cx} 43, \mathrm{p}-\mathrm{S} 368 \mathrm{Cx} 43$ and 

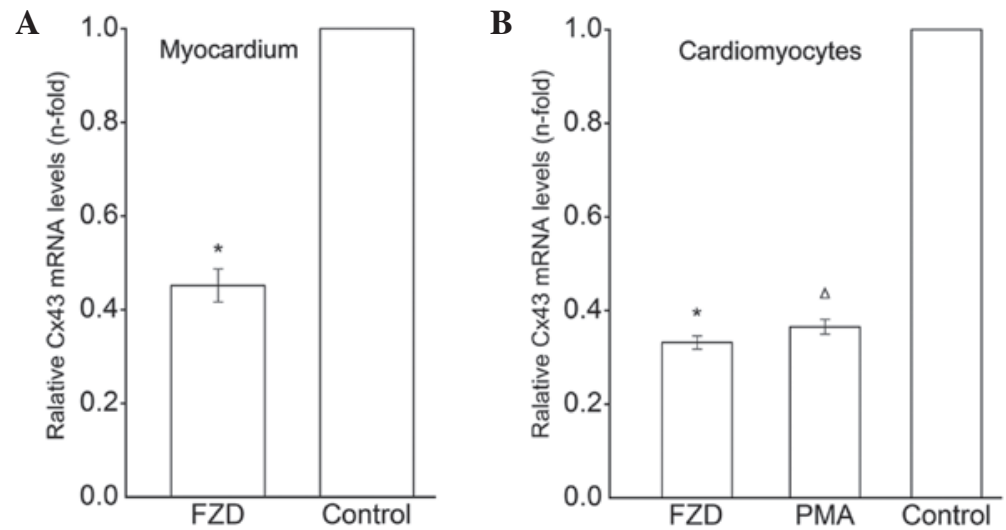

Figure 2. mRNA expression of Cx43 in the rat myocardium and cardiomyocytes. (A) Relative mRNA expression of Cx43 in the myocardium of the FZD and control groups. (B) Relative mRNA expression of Cx43 in the cardiomyocytes of the FZD, PMA and control groups. GAPDH was used as the internal control. ${ }^{*} \mathrm{P}<0.05$ vs. control and ${ }^{\triangle} \mathrm{P}>0.05$ vs. FZD group. Cx43, connexin 43; FZD, furazolidone; PMA, phorbol-12-myristate-13-acetate.
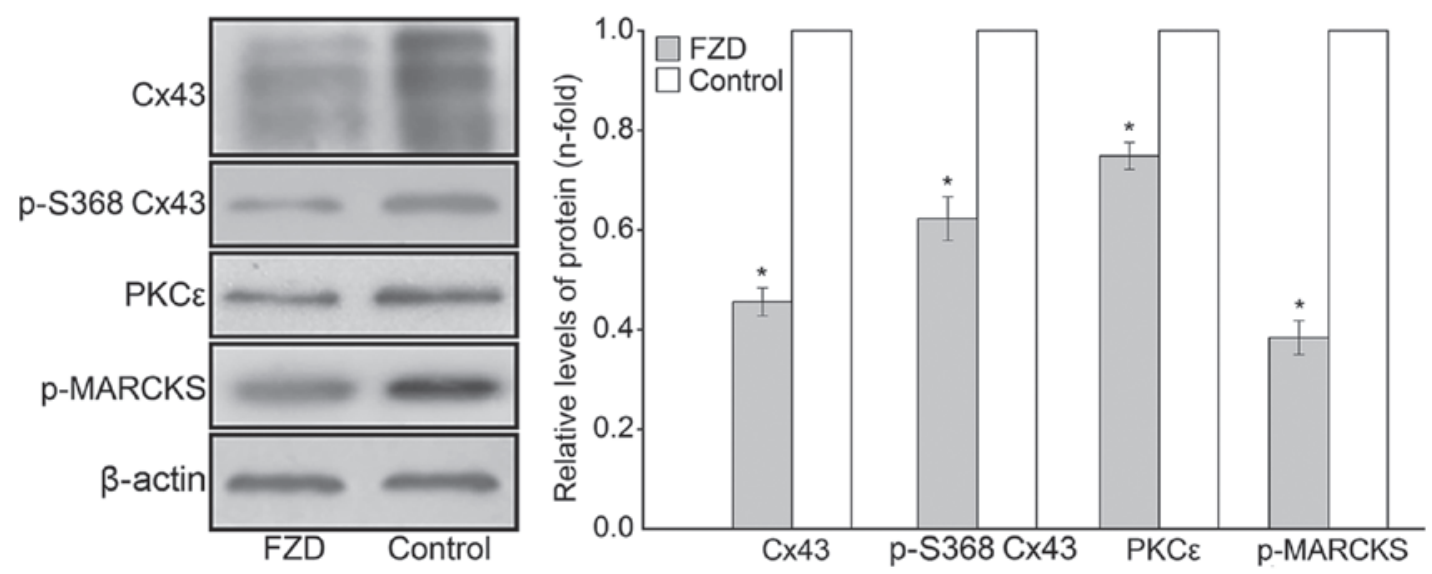

Figure 3. Western blot analysis of the protein expression levels of Cx43, p-S368 Cx43, PKC $\varepsilon$ and p-MARCKS in the rat myocardium of the FZD and control groups. Values are presented as the mean \pm standard deviation relative to $\beta$-actin. " $\mathrm{P}<0.05$ vs. control. Cx 43 , connexin 43 ; p-S368 Cx43, serine 368 -phosphorylated $\mathrm{Cx} 43$; $\mathrm{PKC} \varepsilon$, protein kinase $\mathrm{C} \varepsilon$; p-MARCKS, phosphorylated myristoylated alanine-rich C kinase substrate; FZD, furazolidone.
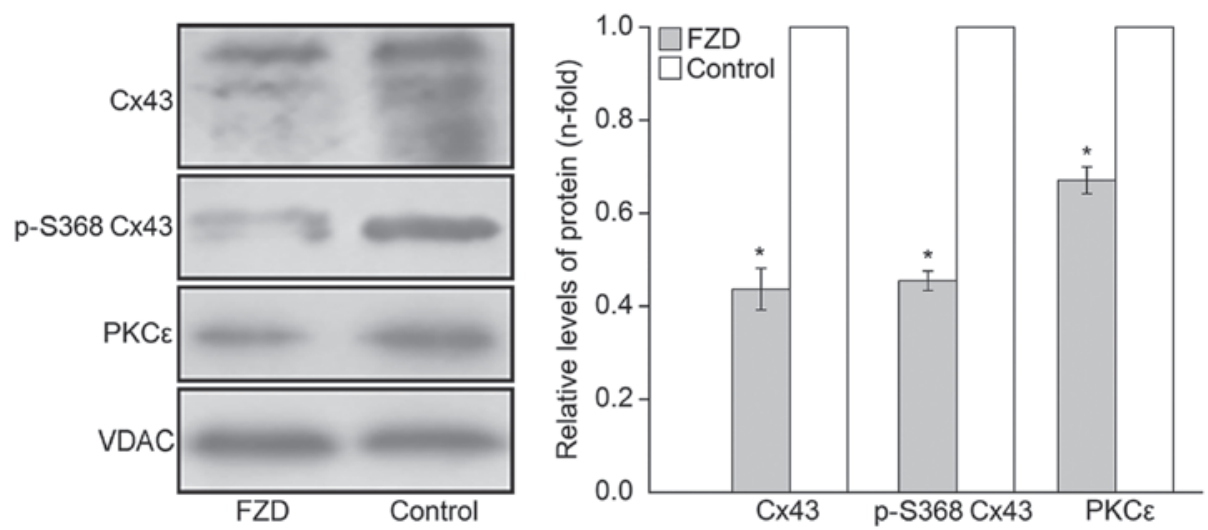

Figure 4. Western blot analysis of the protein expression levels of Cx43, p-S368 Cx43 and PKC $\varepsilon$ in the rat myocardial mitochondria of the FZD and control groups. Values are presented as the mean \pm standard deviation relative to VDAC. ${ }^{*} \mathrm{P}<0.05$ vs. control. Cx43, connexin 43 ; p-S368 Cx43, serine 368 -phosphorylated $\mathrm{Cx} 43$; $\mathrm{PKC} \varepsilon$, protein kinase $\mathrm{C} \varepsilon$; VDAC, voltage-dependent anion channels; FZD, furazolidone.

PKC $\varepsilon$ significantly decreased in the the whole-cell and mitochondrial protein extracts compared with those of the untreated control (P<0.05; Figs. 5 and 6). Furthermore, the phosphorylation of MARCKS was downregulated by $43.6 \pm 2.3 \%$ in the cardiomyocytes $(\mathrm{P}<0.05$, Fig. 5).
Effect of PKCE activation on the phosphorylation of Cx43 at serine 368. As shown in Fig. 5, the p-MARCKS immunoreactivity of the PMA group cells was enhanced by $3.00 \pm 0.20$-fold compared with that of the cells treated with FZD only $(\mathrm{P}<0.05)$. In addition, the FZD-induced inhibition 

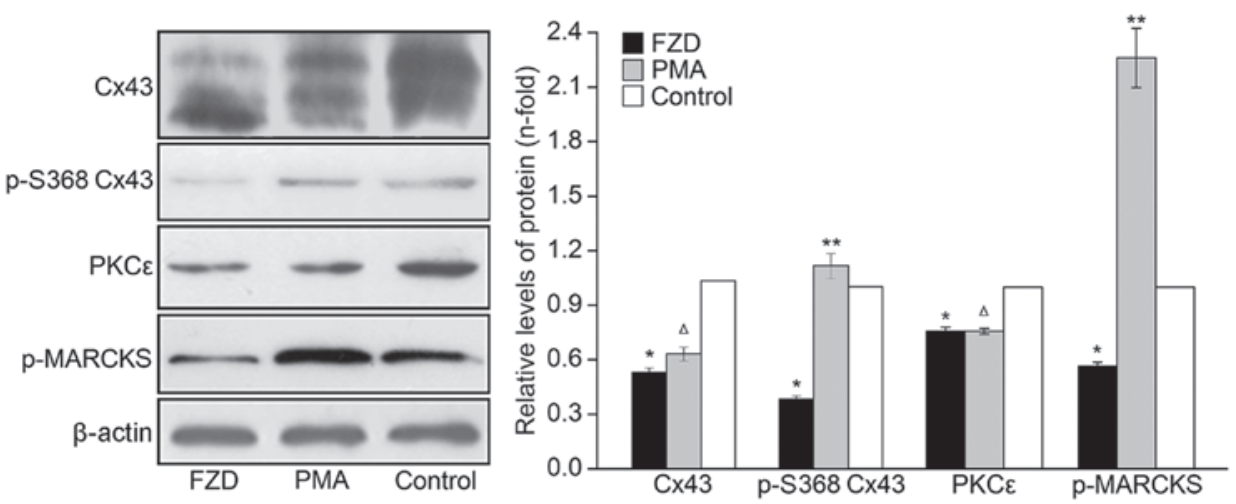

Figure 5. Western blot analysis of the protein expression levels of Cx43, p-S368 Cx43, PKC $\varepsilon$ and p-MARCKS in the rat cardiomyocytes of the FZD, PMA and control groups. Values are presented as the mean \pm standard deviation relative to $\beta$-actin. ${ }^{*} \mathrm{P}<0.05$ vs. control, ${ }^{* *} \mathrm{P}<0.05$ vs. FZD and ${ }^{\Delta} \mathrm{P}>0.05$ vs. FZD. Cx43, connexin 43; p-S368 Cx43, serine 368-phosphorylated Cx43; PKCe, protein kinase C $\varepsilon$; p-MARCKS, phosphorylated myristoylated alanine-rich C kinase substrate; FZD, furazolidone; PMA, phorbol-12-myristate-13-acetate.
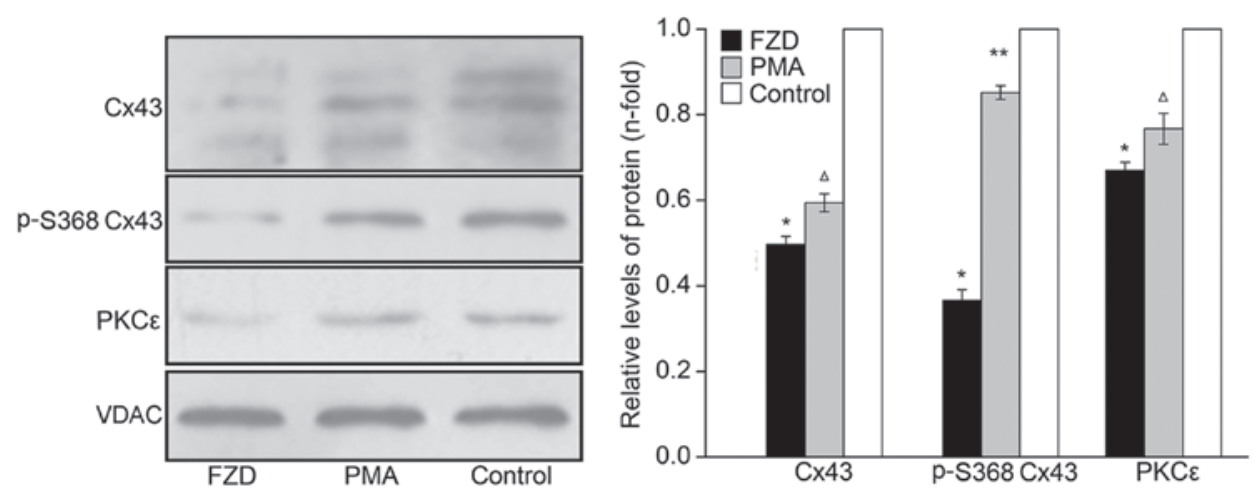

Figure 6. Western blot analysis of the protein expression levels of Cx43, p-S368 Cx43 and PKC 8 in the rat cardiomyocyte mitochondria of the FZD, PMA and control groups. Values are presented as the mean \pm standard deviation relative to VDAC. ${ }^{*} \mathrm{P}<0.05$ vs. control, ${ }^{* *} \mathrm{P}<0.05$ vs. FZD and ${ }^{\triangle} \mathrm{P}>0.05$ vs. FZD. Cx43, connexin 43; p-S368 Cx43, serine 368-phosphorylated Cx43; PKC , protein kinase C $\varepsilon$; VDAC, voltage-dependent anion channels; FZD, furazolidone; PMA, phorbol-12-myristate-13-acetate.

A

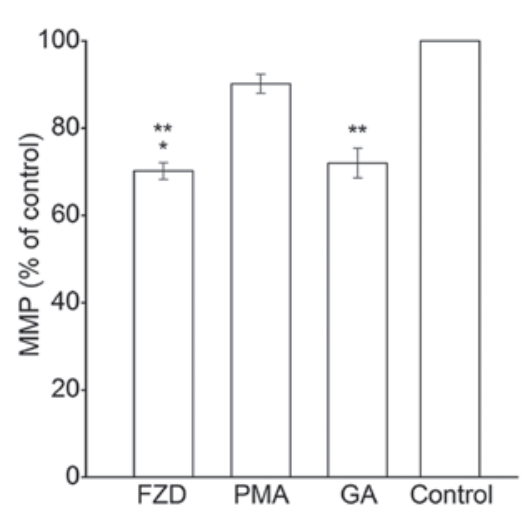

B

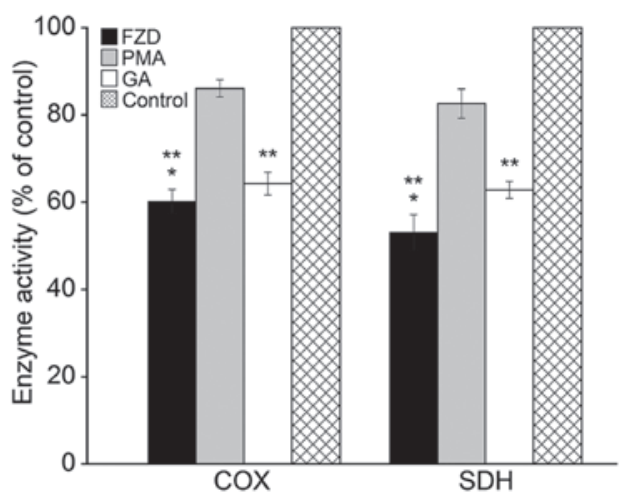

Figure 7. Mitochondrial function of the rat cardiomyocytes. (A) MMP levels and (B) activities of COX and SDH were determined in the mitochondria of the rat cardiomyocytes of the FZD, PMA, GA and control groups. Values are presented as the mean \pm standard deviation. " $\mathrm{P}<0.05$ vs. control, ${ }^{* * *} \mathrm{P}<0.05$ vs. PMA. MMP, mitochondrial membrane potential; COX, cytochrome $c$ oxidase; SDH, succinate dehydrogenase; FZD, furazolidone; PMA, phorbol-12-myristate-13-acetate; GA, $18 \beta$-glycerrhetinic acid.

of Cx43 phosphorylation at S368 was eliminated by PMA in the cardiomyocytes and mitochondria $(\mathrm{P}<0.05$; Figs. 5 and 6$)$. By contrast, no significant differences were observed in the overall levels of $\mathrm{Cx} 43$ in either the cardiomyocyte or mitochondria between the PMA and FZD groups $(\mathrm{P}>0.05$; Figs. 5 and 6).
Role of $m t C x 43$ in regulating mitochondrial function. As shown in Fig. 7, treatment with FZD resulted in a significant decrease in the level of MMP and the activities of COX and SDH compared with those of the control group $(\mathrm{P}<0.05)$. Notably, PMA treatment partially reversed the FZD-induced decrease in MMP levels and COX and SDH 
activities $(\mathrm{P}<0.05)$, and pretreatment with GA eradicated the mitochondrial protective effects of PMA $(\mathrm{P}<0.05)$.

\section{Discussion}

The results of the present study demonstrated that the overall expression levels of $\mathrm{mtCx} 43$ and $\mathrm{p}-\mathrm{S} 368 \mathrm{mtCx} 43$ were downregulated in the myocardial mitochondria of the DCM rat model as well as the mitochondria of the FZD-treated cardiomyocytes, which was accompanied by suppression of the activity of $\mathrm{PKC} \varepsilon$ and mitochondrial function. In addition, the PKC $\varepsilon$ activator, PMA, partially reversed FZD-induced mitochondrial dysfunction via a p-S368 mtCx43-dependent mechanism. These data demonstrated a novel mechanism of mitochondrial dysfunction in the DCM rat model, which may involve the PKC 8 -mediated phosphorylation of Cx43.

$\mathrm{Cx} 43$ is the predominant protein forming gap junctions in the myocardium, which are important in intercellular electrical and metabolic coupling (10). A previous study demonstrated that the myocardial expression of $\mathrm{Cx} 43$ was significantly downregulated and the phosphorylation of $\mathrm{Cx} 43$ was also reduced in patients with non-ischemic cardiomyopathy, and the conduction disorders, which occur due to these abnormalities, may account for arrhythmias in non-ischemic cardiomyopathy (11).

There is increasing evidence for the presence of $\mathrm{Cx} 43$ in the inner mitochondrial membrane of cardiomyocytes, where its level may be upregulated by ischemic preconditioning (2). It has been reported that inhibiting heat shock protein 90 only eliminates the upregulation of $\mathrm{mtCx} 43$, but also ablates the cardioprotection induced by diazoxide (3). Direct single-channel patch-clamp recordings have revealed that the suppression of myocardial $\mathrm{mtCx} 43$ inhibited the function of mitochondrial adenosine triphosphate (ATP)-sensitive $\mathrm{K}^{+}$channels, which serve as important effectors of cytoprotective signaling $(12,13)$. Accordingly, $\mathrm{mtCx} 43$ is important in cardioprotection by ischemic preconditioning via the modulation of mitochondrial ATP-sensitive $\mathrm{K}^{+}$channels. However, whether the level of $\mathrm{mtCx} 43$ was altered and correlated with mitochondrial dysfunction in the pathogenesis of DCM remained to be elucidated. The results of the present study revealed that $\mathrm{mtCx} 43$ was significantly downregulated in the DCM rat myocardium, with a reduction in the overall levels of $\mathrm{Cx} 43$. Furthermore, the expression of p-S368 $\mathrm{mtCx} 43$ was reduced by $\sim 36.8 \%$. In addition, the level of MMP and the activities of COX and SDH were significantly decreased. These findings indicated that the suppression of $\mathrm{mtCx} 43$ and/or its phosphorylation may have been associated with mitochondrial dysfunction in the DCM rats.

$\mathrm{Cx} 43$ is a phosphoprotein, with several phosphorylation sites targeted by different kinases (14). The phosphorylation of $\mathrm{Cx} 43$ at different sites and by different kinases may have different effects. Phosphorylation of $\mathrm{Cx} 43$ at serine 279/282 results in impaired cell communication (15), while enhanced dephosphorylation of $\mathrm{Cx} 43$ contributes to slow conduction in heart failure via increased activation of p21-activated kinase 1 (16). In addition, the phosphorylation status of $\mathrm{Cx} 43$ also affects its suppressive effect on cell proliferation (17). PKC $\varepsilon$ is essential for the phosphorylation of $\mathrm{Cx} 43$ at S368 and is important in ischemic preconditioning-induced cardioprotection by suppressing chemical coupling via $\mathrm{Cx} 43$ gap junction modulation (8). Similar to $\mathrm{Cx} 43$, PKC $\varepsilon$ is also located in the mitochondria, which suggests a possible interaction between $\mathrm{Cx} 43$ and $\mathrm{PKC} \varepsilon$ in the mitochondria (18). Increasing evidence indicates that the phosphorylation status of $\mathrm{Cx} 43$ is not static, but fluctuates in response to cell stress (19-22). In the present study, decreased protein expression of PKC $\varepsilon$ was observed in the myocardial and mitochondrial protein extracts of the DCM rats, and the PKCE activities also decreased by $\sim 60 \%$. Furthermore, the PKC $\varepsilon$ activator, PMA, partially reversed the dephosphorylation of $\mathrm{Cx} 43$ at S368, indicating that the downregulation of PKCE activity was involved in the FZD-induced dephosphorylation of $\mathrm{Cx} 43$.

The results of the present study suggested that the PMA-induced activation of PKC $\varepsilon$ attenuated mitochondrial dysfunction in the cardiomyocytes. Further investigations demonstrated that inactivation of $\mathrm{Cx} 43$ eliminated PMA-induced mitochondrial protection. As the cardiomyocytes were cultured sparsely without cell to cell contact, the targeted inactivation of mtCx43 may have led to the suppression of PMA-induced mitochondrial protection $(23,24)$. These results suggested that activation of PKC $\varepsilon$ may have attenuated mitochondrial dysfunction in a $\mathrm{mtCx} 43$-dependent manner.

In cardiomyocytes, $\mathrm{Cx} 43$ is phosphorylated at different sites by various kinases, including mitogen-associated protein kinase (25), protein kinase A (26), protein kinase B (27), casein kinase 1 (28) and the src tyrosine kinase (29). Further studies are required to elucidate whether the phosphorylation states of Cx43, at sites other than S368, alter or are involved in the pathogenesis of DCM. As a regulator of the mitochondrial physiology, cardiac mtCx43 may target mitochondrial adenosine triphosphate-sensitive $\mathrm{K}^{+}$channels (30). Furthermore, reactive oxygen species formation is reported to be impaired in the cardiomyocytes of $\mathrm{Cx} 43^{--}$mice (4) and cytochrome $c$ and $\mathrm{Ca}^{2+}$ are induced to release from isolated mitochondria by the $\mathrm{Cx} 43$ gap junction inhibitor (31). The present study demonstrated a significant downregulation of $\mathrm{p}-\mathrm{S} 368 \mathrm{mtCx} 43$ in the DCM rat myocardium due to the suppression of PKC $\varepsilon$ activity; however, the precise molecular mechanisms by which $\mathrm{mtCx} 43$ affects mitochondrial function require further elucidation.

In conclusion, the present study revealed that the phosphorylation of mtCx43 at S368 was suppressed in the myocardium of DCM rats and was required for the mitochondrial protective effects of the PKCE activator in FZD-treated cardiomyocytes. These findings suggested a possible mechanism involved in mitochondrial dysfunction in the pathogenesis of DCM and revealed a novel mitochondrial protective role of the PKC $\varepsilon$ activator, PMA, which may offer therapeutic potential for the treatment of DCM.

\section{Acknowledgements}

The present study was supported by The National Science Foundation of China (grant no. 81170209) awarded to Jin Wei.

\section{References}

1. Jeyaraman MM, Srisakuldee W, Nickel BE and Kardami E: Connexin43 phosphorylation and cytoprotection in the heart. Biochim Biophys Acta 2009-2013 1818s, 2012.

2. Boengler K, Dodoni G, Rodriguez-Sinovas A, et al: Connexin 43 in cardiomyocyte mitochondria and its increase by ischemic preconditioning. Cardiovasc Res 67: 234-244, 2005. 
3. Rodriguez-Sinovas A, Boengler K, Cabestrero A, et al: Translocation of connexin 43 to the inner mitochondrial membrane of cardiomyocytes through the heat shock protein 90 -dependent TOM pathway and its importance for cardioprotection. Circ Res 99: 93-101, 2006.

4. Heinzel FR, Luo Y, Li X, et al: Impairment of diazoxide-induced formation of reactive oxygen species and loss of cardioprotection in connexin 43 deficient mice. Circ Res 97: 583-586, 2005.

5. Lu G, Haider HK, Porollo A and Ashraf M: Mitochondria-specific transgenic overexpression of connexin-43 simulates preconditioning-induced cytoprotection of stem cells. Cardiovasc Res 88: 277-286, 2010.

6. Jefferies JL and Towbin JA: Dilated cardiomyopathy. Lancet 375 752-762, 2010.

7. Zhang M, Wei J, Shan H, et al: Calreticulin-STAT3 Signaling Pathway Modulates Mitochondrial Function in a Rat Model of Furazolidone-Induced Dilated Cardiomyopathy. PLoS One 8: e66779, 2013

8. Naitoh K, Yano T, Miura T, et al: Roles of Cx43-associated protein kinases in suppression of gap junction-mediated chemical coupling by ischemic preconditioning. Am J Physiol Heart Circ Physiol 296 H396-H403, 2009.

9. Heidkamp MC, Iyengar R, Szotek EL, et al: Protein kinase Ce-dependent MARCKS phosphorylation in neonatal and adult rat ventricular myocytes. J Mol Cell Cardiol 42: 422-431, 2007.

10. van Veen TA, van Rijen HV and Opthof T: Cardiac gap junction channels: modulation of expression and channel properties. Cardiovasc Res 51: 217-229, 2001

11. Glukhov AV, Fedorov VV, Kalish PW, et al: Conduction remodeling in human end-stage nonischemic left ventricular cardiomyopathy. Circulation 125: 1835-1847, 2012.

12. Rottlaender D, Boengler K, Wolny M, et al: Connexin 43 acts as a cytoprotective mediator of signal transduction by stimulating mitochondrial KATP channels in mouse cardiomyocytes. J Clin Invest 120: 1441-1453, 2010

13. Ahmad Waza A, Andrabi K and Ul Hussain M: Adenosine-triphos phate-sensitive $\mathrm{K}^{+}$channel (Kir6. 1): A novel phosphospecific interaction partner of connexin 43 (Cx43). Exp Cell Res 318: 2559-2566, 2012.

14. Chen VC, Gouw JW, Naus CC and Foster LJ: Connexin multi-site phosphorylation: mass spectrometry-based proteomics fills the gap. Biochim Biophys Acta: 23-34, 1828s, 2013.

15. Chen SC, Kennedy BK and Lampe PD: Phosphorylation of connexin 43 on S279/282 may contribute to laminopathy-associated conduction defects. Exp Cell Res 319: 888-896, 2013

16. Ai X, Jiang A, Ke Y, Solaro RJ and Pogwizd SM: Enhanced activation of p21-activated kinase 1 in heart failure contributes to dephosphorylation of connexin 43. Cardiovasc Res 92: 106-114,2011.

17. Dang X, Jeyaraman M and Kardami E: Regulation of connexin-43-mediated growth inhibition by a phosphorylatable amino-acid is independent of gap junction-forming ability. Mol Cell Biochem 289: 201-207, 2006.
18. Budas GR, Churchill EN, Disatnik M-H, Sun L and Mochly-Rosen D: Mitochondrial import of PKC $\varepsilon$ is mediated by HSP90: a role in cardioprotection from ischaemia and reperfusion injury. Cardiovasc Res 88: 83-92, 2010.

19. Sun L-Q, Gao J-L, Cui C-M, et al: Astrocytic p-connexin 43 regulates neuronal autophagy in the hippocampus following traumatic brain injury in rats. Mol Med Rep 9: 77-82, 2014.

20. Severs NJ, Bruce AF, Dupont E and Rothery S: Remodelling of gap junctions and connexin expression in diseased myocardium. Cardiovasc Res 80: 9-19, 2008.

21. Zador Z, Weiczner R and Mihaly A: Long-lasting dephosphorylation of connexin 43 in acute seizures is regulated by NMDA receptors in the rat cerebral cortex. Mol Med Rep 1: 721-727, 2008

22. Popolo A, Morello S, Sorrentino R and Pinto A: Antiadrenergic effect of adenosine involves connexin 43 turn-over in $\mathrm{H} 9 \mathrm{c} 2$ cells. Eur J Pharmacol 715: 56-61, 2013.

23. Li K, Chi Y, Gao K, et al: Connexin43 hemichannel-mediated regulation of connexin43. PLoS One 8: e58057, 2013.

24. Trudeau K, Muto T and Roy S: Downregulation of mitochondrial connexin 43 by high glucose triggers mitochondrial shape change and cytochrome C release in retinal endothelial cells. Invest Ophthalmol Vis Sci 53: 6675-6681, 2012.

25. Johnstone SR, Kroncke BM, Straub AC, et al: MAPK phosphorylation of connexin 43 promotes binding of cyclin $\mathrm{E}$ and smooth muscle cell proliferation. Circ Res 111: 201-211, 2012.

26. Shah MM, Martinez A-M and Fletcher WH: The connexin43 gap junction protein is phosphorylated by protein kinase $\mathrm{A}$ and protein kinase $\mathrm{C}$ : in vivo and in vitro studies. Mol Cell Biochem 238:57-68, 2002.

27. Park DJ, Wallick CJ, Martyn KD, Lau AF, Jin C and Warn-Cramer BJ: Akt phosphorylates Connexin43 on Ser373, a "mode-1" binding site for 14-3-3. Cell Commun Adhes 14: 211-226, 2007

28. Cooper CD and Lampe PD: Casein kinase 1 regulates connexin-43 gap junction assembly. J Biol Chem 277: 44962-44968, 2002

29. Lin R, Martyn KD, Guyette CV, Lau AF and Warn-Cramer BJ: $\mathrm{v}$-Src tyrosine phosphorylation of connexin43: regulation of gap junction communication and effects on cell transformation. Cell Commun Adhes 13: 199-216, 2006.

30. Rottlaender D, Boengler K, Wolny M, et al: Glycogen synthase kinase $3 \beta$ transfers cytoprotective signaling through connexin 43 onto mitochondrial ATP-sensitive K+ channels. Proc Natl Acad Sci USA 109: E242-E251, 2012.

31. Goubaeva F, Mikami M, Giardina S, Ding B, Abe J and Yang J: Cardiac mitochondrial connexin 43 regulates apoptosis. Biochem Biophys Res Commun 352: 97-103, 2007. 